\title{
El cuerpo negro y femenino en la publicidad brasileña
}

\author{
The black and female body in Brazilian advertising
}

Thyalla Sena Solon y Verbena Córdula Almeida

Universidad Estatal de Santa Cruz (Brasil)

thyalla_solon@hotmail.com; profverbenacordula@gmail.com

\section{Resumen}

El presente trabajo contiene un estudio respecto a la representación de las personas negras en la publicidad brasileña, y toma como corpus de análisis 41 carteles fotografiados en las principales avenidas de la ciudad de Itabuna, ubicada en el estado de Bahía (noroeste del país). Los resultados del estudio se exponen a partir de un análisis cuantitativo y cualitativo y demuestran que la situación privilegiada de las personas blancas se traspone para la publicidad, donde el uso de la imagen no solamente construye un rasgo de la sociedad contemporánea, sino que la existencia de la publicidad de la imagen es también parte de las relaciones sociales en el universo del imaginario y de la cultura.

Palabras clave: publicidad; racismo; Brasil; hombre negro; mujer negra. 


\section{Abstract}

The present work contains a study regarding the representation of black people in Brazilian advertising, and takes as object of study 41 billboards photographed in the main avenues of the city of Itabuna, located in the state of Bahia (northwest of the country). The results of the study are presented on the basis of a quantitative and qualitative analysis and show that the privileged situation of white people is transferred to publicity, where the use of the image not only reflects a feature of contemporary society, but the existence of the publicity of the image is also a reflection of the social relations in the universe of the imaginary and the culture.

Keywords: publicity; racism; Brazil; black man; black woman.

Actualmente en Brasil es posible percibir una presencia mayor de personas negras en los medios en general, y en la publicidad en particular, producto del aumento de una clase media negra; $y$, también, por la presión que las organizaciones negras vienen ejerciendo a lo largo del tiempo en contra del racismo. Según datos del Instituto Brasileño de Geografía y Estadística (IBGE), entre 2005 y 2015 (1) hubo un incremento del número de negros entre los brasileños más ricos, de $11,4 \%$ a $17,8 \%$. Sin embargo, el mismo Instituto apunta que las desigualdades entre negros y blancos aún son emblemáticas en el país, y que entre la población más pobre, tres de cada cuatro son personas negras. Datos del mismo Instituto, divulgado en 2015, demuestran que la parcela de la población brasileña que conforma el $10 \%$ más pobre, con renta media de 130 reales por persona en la familia (aproximadamente 50 dólares) es mayoritariamente formada por personas negras.

La Secretaría de Políticas para la Promoción de la Igualdad Racial (SEPIR) publicó, en ese mismo año, que el mayor contingente de la población carcelaria del país está conformado por personas negras. Estudio del IBGE de 2015 señala que, a pesar del número de negros presentes en la enseñanza superior haber duplicado, por influencia de políticas públicas, solamente un $12,8 \%$ de esa población alcanzó la Universidad; en contrapartida, el número de blancos en ese nivel de escolarización era de $25,5 \%$. Cuando el estudio se refiere al saneamiento (agua corriente y cloaca), en los hogares de familias negras el porcentaje es de $55,3 \%$, en cuanto en los hogares de familias blancas ese número sube para $71,9 \%$.

Según Cunha (2014: 105), en 2011, mientras las familias negras recibían, en promedio, una renta de $R \$ 1.978,30$, la renta de los blancos era de $R \$ 3.465,30$, un $75,2 \%$ superior. La autora subraya que esa y otras asimetrías raciales "apuntan que Brasil se caracteriza por ser un país 
donde existe discriminación racial y que, a pesar de haber alcanzado algunas conquistas concretas, todavía está lejos de lograr la equidad racial", ya que las diferencias significativas en la apropiación de bienes producidos y del acceso a los servicios públicos ofrecidos siguen impactando negativamente en la vida de la población negra.

Estudios del IBGE, así como del Instituto de Encuestas Económicas Aplicadas (IPEA), del Consejo Nacional de Justicia (CNJ) y de la campaña denominada "SUS (Sistema Único de Salud) sin racismo" apuntan que la tasa de analfabetismo (4) entre las mujeres negras es dos veces mayor que entre las mujeres blancas; que el acceso a los servicios de salud por las mujeres blancas es muy superior a lo de las mujeres negras - por ejemplo, de cada 100 mujeres que mueren debido al parto, 60 son negras; que del total de mujeres encarceladas (5), más de la mitad son negras ( $68 \%$ contra $32 \%$ de blancas); que en $2015,77 \%$ de las mujeres blancas recibieron orientaciones respecto a la importancia de alimentar a sus hijos con la leche materna y solamente $62,5 \%$ de las mujeres negras recibieron las mismas informaciones (6). La situación privilegiada de personas blancas se da debido al proceso social e histórico marcado por el "blanqueamiento de la población", lo cual, para los racistas, sería el indicativo de la "evolución social". Ello se dio a partir de un discurso tradicional, ampliamente aceptado en el Brasil del siglo XIX y la primera mitad del XX -que defendía la eugenesia- buscando un proceso de blanqueamiento de las razas, hasta que se lograse una composición étnica satisfactoria. Así, como afirma Góes (2015: 213), la política eugenésica se convierte en ideología, pues sus partícipes pasan a defender y emprender una práctica en el sentido de amplificar, con el objetivo de consolidar las leyes eugenésicas, los movimientos de encapsulamientos de los denominados locos, indeseables a las instituciones manicomiales; la efectividad del racismo mediante segregación espacial de negros en las favelas, en los lugares menos favorecidos.

Aunque la convivencia entre blancos y negros sea visible en el contexto social e histórico de Brasil, y en el presente no haya ninguna ley que oficialice la discriminación, es esencial subrayar la existencia de esas desigualdades construidas por la ideología del sistema esclavista; así como cuestionar la supuesta democracia racial existente en el país, ya que solamente sirvió para camuflar prejuicios, porque, conforme demuestran los datos socioeconómicos, los negros y los blancos aún no disfrutan de los mismos derechos.

Por considerar que el racismo está presente en todos los ámbitos de la sociedad brasileña, y por entender que la falta de representación -o la representación estereotipada de los negroses, también, una de las muchas formas de racismo, a lo largo de este trabajo se intenta observar si eso ocurre en la ciudad de Itabuna, integrada por 221.000 habitantes (de acuerdo a encuesta del IBGE 2017) -en su mayoría compuesta por hombres y mujeres de raza negra-. Así, el presente estudio contiene una reflexión sobre la representación negra a partir del análisis de las posiciones ocupadas por personas negras en 41 carteles ubicadas en las 
principales avenidas de la ciudad de Itabuna, Bahía, Brasil. Para ello, el estudio fue guiado a partir de tres preguntas: ¿Contienen representaciones de personas negras los anuncios dispuestos en los carteles de Itabuna? Si es así, ¿qué clases de representaciones están presentes? ¿De qué manera el proceso social e histórico de los negros en Brasil, marcado por el racismo, puede influenciar la publicidad a la preferencia por la cara representada en los carteles?

La metodología para la construcción de la investigación se basó en tres pasos: el registro fotográfico de los carteles; la identificación de la presencia o ausencia de personas negras; la evaluación de las representaciones de esas personas presentes en los referidos carteles. Los datos fueron recogidos a partir de las fotografías tomadas desde el 1 de abril al 5 de junio de 2015, en las principales avenidas de la ciudad de Itabuna (Juracy Magalhaes, Aziz Maron y Princesa Isabel). Los resultados del estudio se exponen a partir de un análisis cuantitativo y cualitativo. Los criterios para la identificación de las personas negras en las publicidades objeto de este estudio fueron los aspectos físicos, a través de atributos que culturalmente construyen un consenso sobre el fenotipo de la población negra, como el pelo rizado, la piel oscura y las narices gruesas.

Los análisis cuantitativos si refieren al registro del número de personas negras presentes en todos los anuncios fotografiados, en comparación con el número de personas blancas, los cuales están representados por medio de gráficos. Lo mismo se hizo con las publicidades que incluyen blancos y negros (cuáles son los productos que ponen esas imágenes), así como distinguimos, también a través de tabla, la aparición de negros y blancos por edad y género. Así, el estudio cuantitativo supuso comparar los datos obtenidos a partir del corpus de análisis para presuponer generalizaciones (Goldenberg, 1997). La interpretación de las imágenes y la observación sobre la representación social del individuo negro en los carteles fueron consideradas con el fin de describir la posición de los hombres negros y las mujeres negras en las publicidades. En este caso fue utilizado el análisis cualitativo, que se caracteriza no solamente por el perfil descriptivo, sino también interpretativo, capaz de descifrar los símbolos presentes en un objeto, a partir de una lectura social. La investigación del contexto en el que se inserta el objeto confiere al método cualitativo un enfoque más amplio, así como permite al investigador un procedimiento más racional y, al mismo tiempo, intuitivo. Así, a través del análisis cualitativo fue posible verificar cuestiones no cuantificables que pertenecen al mundo de la cultura, tales como signos, valores, comportamientos etc., los cuales, como afirman Marcone y Lakatos (2011), se relacionan con la complejidad humana. A partir de esos procedimientos fueron analizados los discursos contenidos en las imágenes encontrados en las publicidades, con el fin de detectar las evidencias que demuestren la presencia o ausencia de racismo en ellas. 


\section{El cuerpo negro, la comunicación y la publicidad}

Guimarães (2004) afirma que el color de la piel ha adquirido el poder de representación de la posición social de los individuos. Aunque la presencia de personas negras en el mundo social y en los medios de comunicación sea visible, la representación en esta segunda instancia se desarrolla bajo la sumisión a la norma blanca como condición de aceptación: un rostro mestizo, en el cual los rasgos africanos, especialmente la nariz, son leves e incluso el pelo rizado para pasar la imagen de naturalidad (Strozenberg, 2005). Las marcas de la demagogia presentes en el sistema colonial, que describen a la persona negra como "estéticamente fea, sucia y poco civilizada" (Mattos, 2009) se hacen presentes con "ropa nueva", como dice el mismo autor cuando afirma que las imágenes de los negros son frecuentemente asociadas con "figuras extrañas", "sinvergüenzas" o "delincuentes".

En el sistema brasileño posterior a la esclavitud, las personas negras eran tratadas como extranjeras debido a la formación de una identidad nacional basada en la apreciación del eurocentrismo (Nascimento, 2003). En aquel contexto, el cuerpo fue convertido en el principal elemento para la construcción de prejuicio. Términos despectivos creados en la ideología de la esclavitud para designar a los negros sirvieron -y todavía sirven- para calificar los cuerpos. Desde la perspectiva del sistema esclavista era necesaria la creación de estereotipos como una de las justificaciones de la esclavitud. Según Abrahão y Soares (2011), diferentemente de la categoría homo sapiens destinada a los blancos, las representaciones hegemónicas respecto a los negros sugieren que los últimos serían destituidos de la "racionalidad", en cuanto los primeros dotados de inteligencia.

Así, el lugar social que las representaciones destinan a los negros es distinto de aquellos considerados "superiores" o "intelectuales", como la ciencia, la política o los negocios, por ejemplo. Fanon (1986: 161) afirma que en el "inconsciente colectivo" hay una síntesis del mal como pertenecientes al individuo negro, debido a la herencia del sistema esclavista, negro es igual a "feo", "pecado", "tiniebla", "inmoral". Para reforzar ese imaginario, mendigos y "sinvergüenzas" que deambulan por las calles, por ejemplo, son casi exclusivamente negros. Los conceptos de Fanon podrían explicar el sentido utilizado para la belleza en nuestro entorno, donde el blanco es convertido en el mistificador y, al mismo tiempo, se mistifica (a la luz de la superioridad), lo que permite que los negros no encuentren identificación en las representaciones diseminadas. Por lo tanto, el signo (asociación con delincuentes, sin vergüenzas) de sus cuerpos [los de personas negras] conduce a la negación de la observación del "yo social", ya que sólo el estigma del cuerpo tiene el poder de certificación personal (Breton, 2007). 
Por esa lógica, a los blancos se les imputa la imagen de "bondad", que, históricamente, se asocia con la belleza, y, a su vez, según Platón citado por Eco (2004: 5) significa "armonía y proporción de las partes". Sin embargo, Rosenkranz en palabras de Eco (2004) explica que el "feo" sólo existe cuando el "hermoso" sobrevive; y que esta dicotomía está presente en muchas sociedades, lo que equivale a la clasificación como "hermoso" de un grupo particular sobre otro. Esta división se basa en la apreciación de la estética helenística (7) (D'adesky, 2000), la cual excluye a la mayor parte de la población.

En la publicidad presente en los medios de comunicación es muy común el uso de personas; y la selección de éstas para despertar la atención depende de la potencia de la imagen, es decir, poseer un rostro que la mayor parte de la sociedad clasifique como hermoso. Las piezas publicitarias, además de vender marcas, también venden los valores sociales, como, por ejemplo, la belleza. El problema, sin embargo, es "la primacía de los grupos que supuestamente piensan encarnar el concepto de la belleza, el ideal estético, en lugar de grupos depreciados" (D'adesky, 2000: 70). Así, la imagen puede ser un medio para observar la percepción de la realidad en la publicidad, que se convirtió en el objeto discursivo central de los procesos comunicativos (Retondar, 2007).

La imagen no es preponderante solamente en los medios de comunicación, sino que es, en sí misma, un fenómeno presente en las sociedades contemporáneas de un modo general, pues la dimensión estética se ha convertido en uno de los valores primordiales; la imagen se ha convertido en algo fundamental para apoyar la idolatría de la apariencia. Bajo ese contexto, la proyección de la realidad basada en la importancia del factor estético se presenta casi siempre revestido de estereotipos con imágenes irreales o de fantasía. Aunque no sea la realidad, las situaciones presentadas por la publicidad hacen del símbolo del imaginario más atractivo que la propia realidad, debido a la aceptación del público, que idealiza "la sociedad del espectáculo" (8) (Debord, 1967). Esta estructura de la imagen es crucial para la realización de lo irreal.

Sin embargo, la existencia de la publicidad de la imagen es también un reflejo de las relaciones sociales "en el plano imaginario y de la cultura" (Debord, 1967). Este contexto también es posible debido a la aparición de nuevas tecnologías audiovisuales, las cuales dieron lugar a una comunicación más sofisticada y atractiva que transformó el discurso, ya que la nuevas sociabilidades se basan, muchas veces, en la reproducción de las representaciones y símbolos, de manera "estetizada" (Retondar, 2007). Este contexto delimita la influencia de la publicidad que, por ser una técnica de la comunicación social, sirve para tornar público y volver popular lo que "debe" ser consumido, además de expresar las relaciones de poder a través de las representaciones que exaltan o señalan la posición de clase social o de raza, por ejemplo. En la concepción de Devid Le Breton (2007), el rostro es la parte a través de la cual son reconocidos las identidades sociales y el "otro". Las diferencias, para este teórico, son convertidas en razones para grandes preguntas para los individuos. Al asociar esta discusión a 
la cuestión del racismo y la invisibilización de las personas negras en la sociedad brasileña, es necesario añadir que, al mismo tiempo, el cuerpo es convertido en lugar de valoración y, también, por diversas razones (como el racismo), lugar para el rechazo.

\section{Negros y negras en los carteles de Itabuna}

Desde un punto de vista cuantitativo fue posible ver, en nuestra muestra formada por cuarenta y un (41) carteles, que hay un número muy pequeño de la representación de los individuos negros en los carteles de Itabuna, en comparación con la representación de individuos blancos. Del total, sólo siete contenían personas negras, en cuanto treinta y cuatro presentaban personas blancas, como demuestra el Gráfico 1.

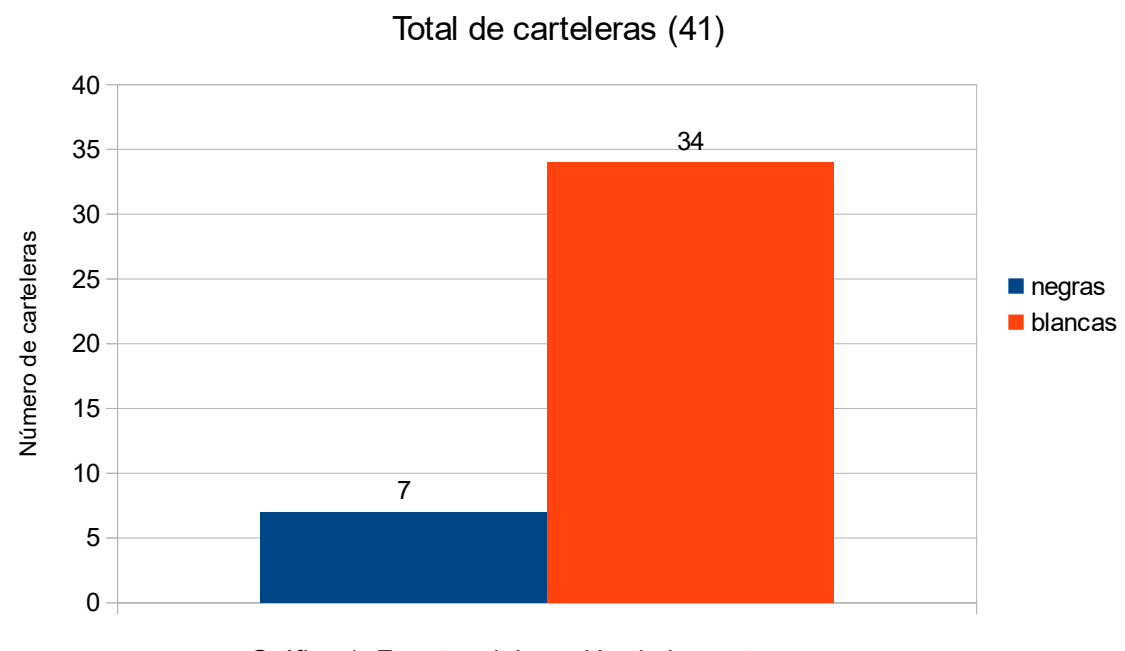

Gráfico 1. Fuente: elaboración de las autoras.

Los temas de las publicidades con personas blancas estaban relacionados con la educación privada (con ocho carteles); tiendas de ropa (con seis carteles); seguidos de anuncios de estética (con cuatro carteles); de salud (con tres carteles). Los otros temas abordaban zapaterías, tiendas de utensilios para cocina, tiendas de productos para niños, canales de televisión, ópticas, tiendas para novias, publicidad gubernamental, tienda de muebles, transporte y fotografía (Gráfico 2). 
Temas de las carteleras con protagonistas blancos

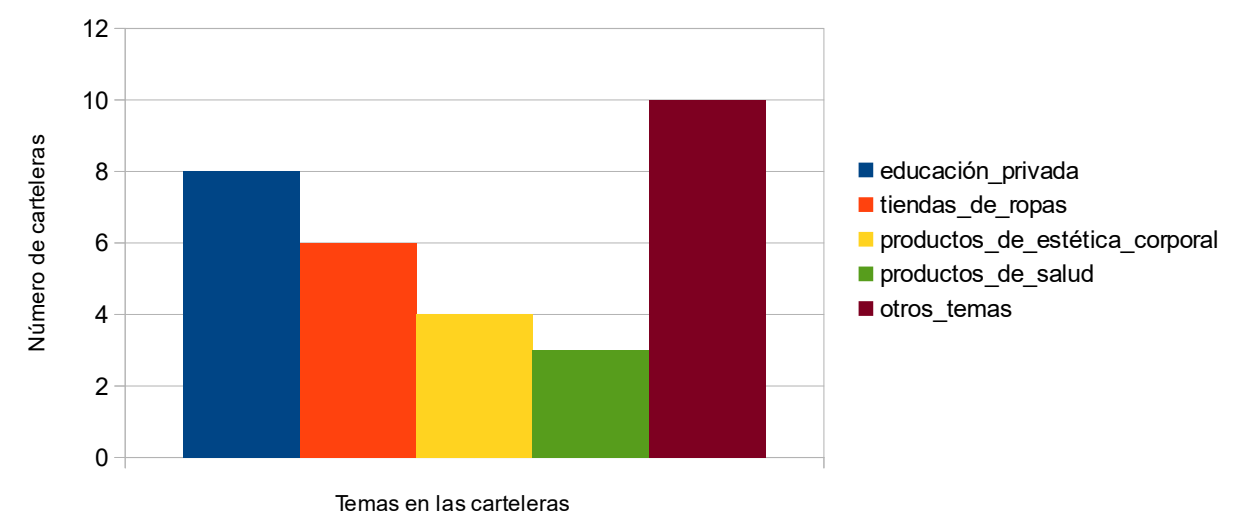

Gráfico 2. Fuente: elaboración de las autoras.

Los anuncios en los que sólo aparecían personas negras eran dos. Los otros cinco en los cuales contenían la presencia de personas negras, éstas no eran las protagonistas de las publicidades y aparecían como acompañantes. Las publicidades en las que solamente aparecían personas negras contenían mensajes de tiendas de materiales para la construcción (la mercadería estaba en promoción) y un sitio web cuyo autor/propietario era el protagonista de la publicidad. Las otras publicidades en las que estaban presentes individuos negros, eran: una anunciando tienda de ropa; otra anunciando revista; una anunciando productos para adelgazar; dos anunciando empresa de telefonía móvil, conforme el Gráfico 3:

Temas y cantidad de carteleras con personas negras

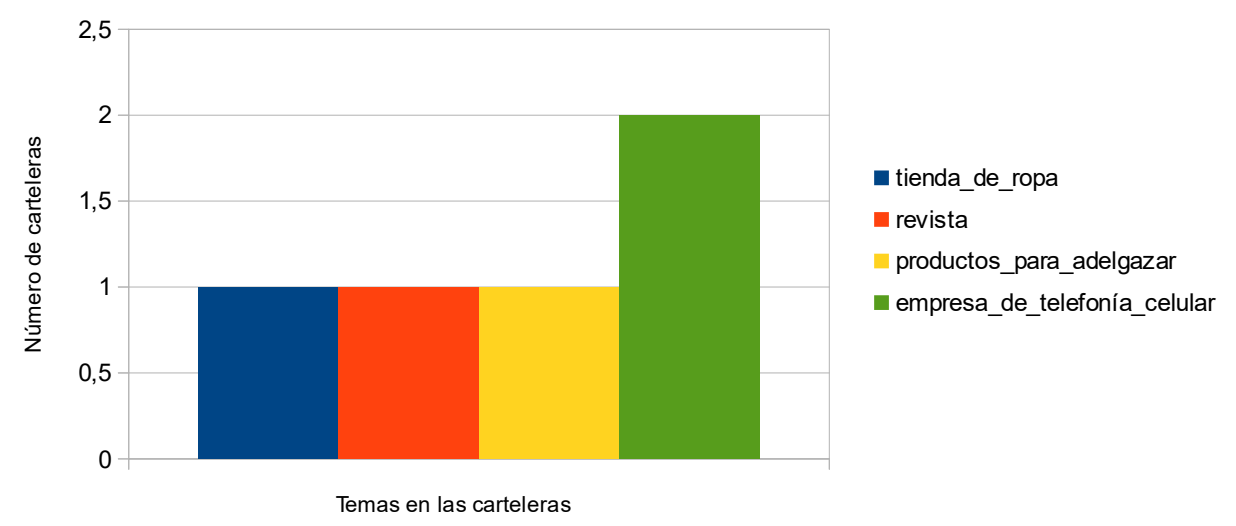

Gráfico 3. Fuente: elaboración de las autoras. 
En cuanto a los anuncios con personas blancas, en veintiún carteles, tanto los hombres como las mujeres y adolescentes aparecen solos; en las otras trece carteles restantes aparecen en conjunto. En treinta y cuatro anuncios donde figuran personas blancas, hay treinta y dos mujeres -de estas, cinco niñas y una adolescente-; además de veinte hombres; nueve niños y dos adolescentes del sexo masculino, conforme se puede observar en el gráfico. Y en los siete carteles en las que aparecen personas negras, hay dos mujeres; ninguna niña, ningún niño; una adolescente; cuatro hombres, y ningún adolescente del sexo masculino, como está representado la Tabla 1.

\begin{tabular}{|c|c|c|}
\hline & $\begin{array}{c}\text { Carteles donde aparecen } \\
\text { personas blancas (por edad } \\
\text { y género) }\end{array}$ & $\begin{array}{c}\text { Carteles donde aparecen } \\
\text { personas negras (por edad y } \\
\text { género) }\end{array}$ \\
\hline Total de mujeres & 32 & 2 \\
\hline Total de niñas & 5 & 0 \\
\hline $\begin{array}{c}\text { Total de adolescentes de } \\
\text { sexo femenino }\end{array}$ & 1 & 4 \\
\hline Total de hombres & 20 & 0 \\
\hline Total de niños & 9 & 0 \\
\hline $\begin{array}{c}\text { Total de adolescentes de } \\
\text { sexo masculino }\end{array}$ & 2 & \\
\hline
\end{tabular}

Tabla 1: cantidad de negros y blancos por edad y género. Fuente: elaboración de las autoras.

Es posible observar, con base en los gráficos y en la tabla, que la aparición de personas blancas es significativamente superior si comparada con la aparición de personas negras, independientemente de edad y género. Así como también es perceptible la variedad de productos presentes en los carteles donde los protagonistas de los anuncios son personas blancas. Demuestra, aún, que las personas negras no están presentes en varios contextos, como la educación privada y la salud, por ejemplo, conforme lo demuestran los carteles donde figuran esas publicidades. 


\section{El "lugar" de la mujer negra}

Otro aspecto observado en nuestro estudio está relacionado con el género. La representación femenina es predominante, pero los datos recogidos muestran que, más allá de las jerarquías creadas por la ideología sexista que pueden dirigirse a las mujeres, hay una ideología racista que condiciona un análisis específico para las demandas de las mujeres negras, porque a partir de las ideologías sexistas y racistas ese segmento de la población pasa a ser más propenso a sufrir las consecuencias de la desigualdad social. Eso es visto a través de las representaciones sociales que se desprenden de nuestro objeto de estudio.

Desde el punto de vista cualitativo, la desigualdad en la representación de los negros en los carteles de la ciudad de Itabuna muestra, además de la problemática del concepto de belleza y del "racismo cordial" (racismo disimulado), las posiciones sociales discriminatorias dirigidas a los hombres y a las mujeres de raza negra. El protagonismo del individuo negro -hombresolamente fue notable en un único cartel, la cual hace referencia a un almacén de materiales de construcción con productos en liquidación, conforme demuestra la imagen a seguir (Fotografía 1), además de un cartel con auto-promoción, ya que se trata del anuncio de una web protagonizado por su propietario. Cuando tenemos en cuenta que la población negra conforma la mayoría más pobre de la sociedad brasileña (por razones históricas), su proyección aparece más asociada a productos de mayor accesibilidad, o sea, los productos básicos. Por lo tanto, es importante tener en cuenta que no es sólo una coincidencia la apariencia de la persona negra en el cartel donde publicita una promoción.

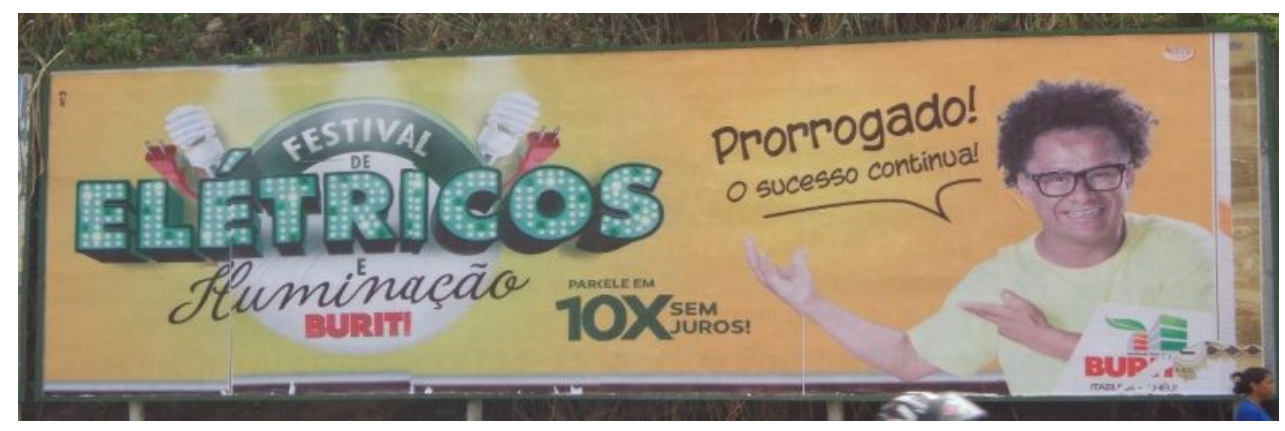

Fotografía 1: cartel con protagonista negro (las autoras).

Aunque las mujeres negras todavía sean las más pobres de la sociedad brasileña -según el Instituto de Investigación Económica Aplicada (IPEA)-, es posible medir, utilizando los datos recogidos en nuestra investigación que, además de no presentar a estas mujeres en diversas áreas sociales -tales como la educación, por ejemplo- las ponen en desventaja, porque cuando están presentes en un anuncio es posible ver que su participación implica algún parámetro 
racista que trata de ocultarlas, a ejemplo de la no aparición definida de su rostro, como se puede ver en la siguiente imagen (Fotografía 2).

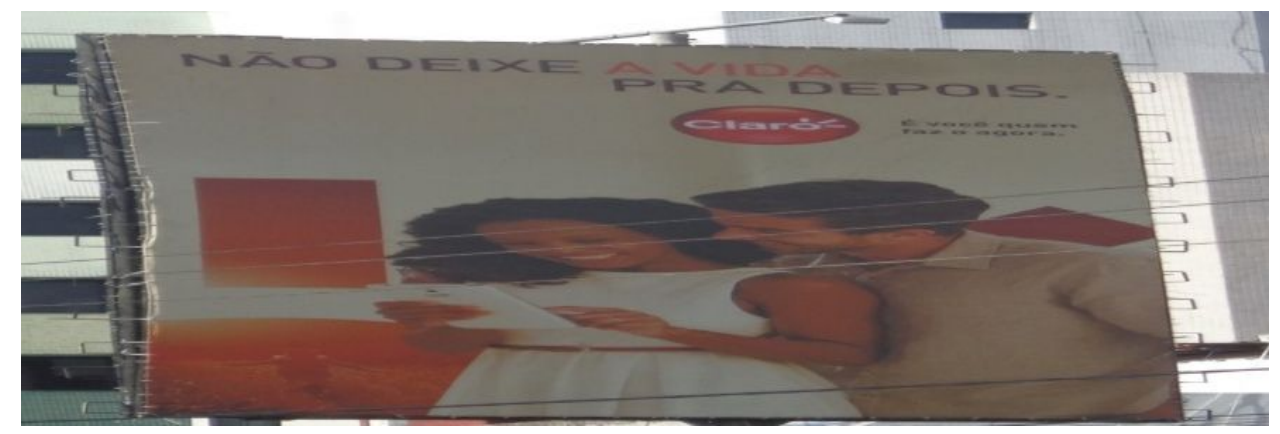

Fotografía 2: Cartel con mujer negra (las autoras).

Aun desde el punto de vista cualitativo, el anuncio (Fotografía 2) muestra la "representación" de la mujer negra (única mujer negra protagonista de los carteles fotografiadas para esta investigación), pero pasa por un proceso distinto de otros anuncios con representación femenina: el rostro no es el objeto de concentración y si la acción. La postura y la colocación se ajustan a las cuestiones planteadas por Sant'Ana (2015), como el "mimetismo estereotipado/identificación entre la marca y el individuo", porque, en esa publicidad, la mujer negra usa ropa y utensilios (cinturón) con colores de la marca del producto que anuncia, y esta posición afecta a la persona que observa la publicidad, "conduciéndola" hacia una fuerte asociación con el producto - el "mimetismo cromático", en el que la persona se convierte en el "objeto/marca". Es decir, el individuo, [en este caso la mujer negra de la pieza publicitaria sobre la cual nos referimos] se vuelve solamente un complemento de la publicidad, lo que difiere de otros contextos observados en los que se utilizaron las modelos para atraer la mirada en la pieza publicitaria, como en la Fotografía 3.

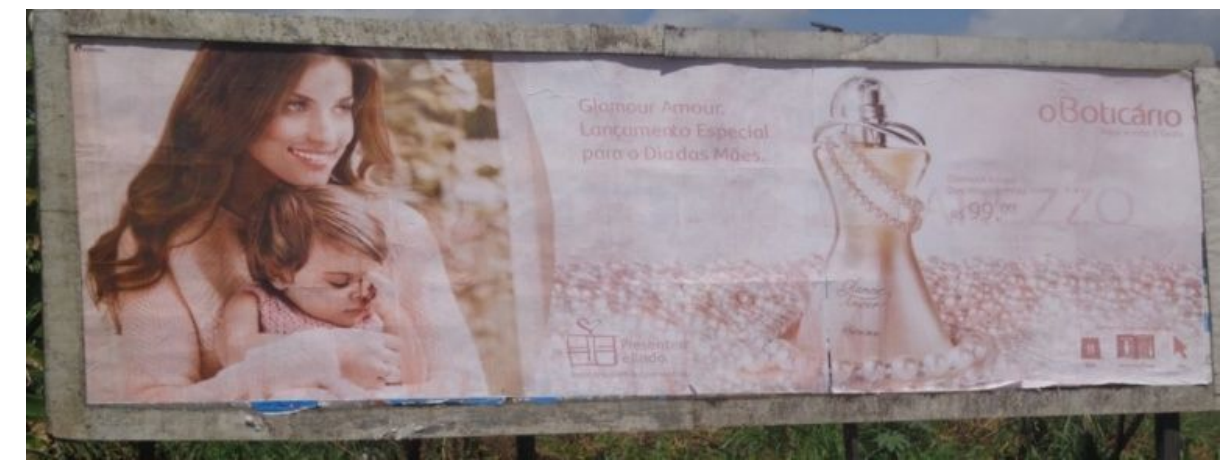

Fotografía 3: catelera con mujer blanca (las autoras). 
A diferencia de la fotografía anterior, en la Fotografía 3 también es evidente la existencia de la producción de un "mimetismo cromático" basado en el color del producto. Sin embargo, es posible identificar que, en esta situación, la modelo no está poniéndose perfume, o sea, no está usando el producto como hace la modelo de la Fotografía 2; el rostro de la mujer blanca aparece con nitidez. Es posible inferir que la imagen humana, en esta situación, es un truco utilizado para atraer la atención de la audiencia a través de la "belleza" de la modelo y su expresión de felicidad, que podrían seducir, encantar. El proceso de memorización de la Figura 2 sería de otro modo, ya que, probablemente, la cara de la modelo no sería recordada como la de la modelo de la figura 3, porque estaría en la acción y no en el aspecto de su rostro o de su la belleza, de ahí que no sería "reconocida".

\section{Las (¿) representaciones (?) y sus significados}

Los resultados de este estudio nos permiten observar cómo los rostros que se encuentran distribuidos por la ciudad de Itabuna (por medio de la publicidad) demuestran la construcción de la identidad en nuestra sociedad. Mensajes dirigidos a los pobres poseen un rostro negro. Por este motivo, a partir de los estudios realizados en esta ciudad es posible diagnosticar la situación del individuo negro a través del posicionamiento de su rostro en esta sociedad. Breton (2007) conceptualiza el racismo como una especie de maniobra para "clonar" a toda la gente negra, porque entonces todos se tornarían iguales, reunidas en torno a un "cuerpo colectivo" Ilamado cuerpo negro. De esta manera, se eliminan las diferencias culturales y la presencia del individuo negro se reduce a su cuerpo. "Se trata de las condiciones de vida del hombre que son producto inalterable de su cuerpo" (Breton, 2007: 73).

La falta de representación de los negros, en las imágenes, permite la lectura de la presencia de las personas blancas como "mejores", porque están representadas; en consecuencia, la apariencia se convierte en un elemento de sujeción, además del agravante de clase, ya que la mayoría de los productos anunciados en los medios no son utilizados por los grupos sociales en desventaja económica (en su mayoría compuestos por personas negras y procedentes de las zonas rurales). Esto favorece la depreciación, el perjuicio en contra de los pobres (Breton, 2007).

Por lo tanto, los rasgos negroides en un contexto racista son convertidos en defectos. La nariz ancha, el pelo rizado y el color negro son puestos para establecer parámetros para medir la "fealdad". Así, por ejemplo, una mujer negra con el pelo lacio se torna "menos fea" que una de pelo rizado. En este contexto, es posible afirmar que la sociedad de Itabuna -así como la brasileña en general- aún no ha logrado eliminar las desigualdades en las relaciones sociales, corroborando lo que dice Costa (2002), para quién no apreciamos la igualdad como un valor, 
sino que naturalizamos las desigualdades basadas en los rasgos físicos, además de la creación de la categoría "raza" para explicar las diferencias étnicas. Esta situación demuestra que el inconsciente colectivo (Fanon, 1986) no acepta al individuo negro.

La discusión sobre la representación social no se basa únicamente en la cuestión de la sub representación de algunos grupos sociales, pero es importante tener en cuenta que la permanencia de la ideología dominante también depende de la fuerza de su representación, que sirve tanto para ayudar a mantener el status de la clase hegemónica, como para justificar su hegemonía y "superioridad". Las representaciones sociales que nacen del imaginario social reflejan las condiciones y la aceptación de la sociedad de los parámetros que permiten la legitimación, o la ruptura de la desigualdad entre los individuos. Ellas son una variante de nuestro contexto cotidiano; es decir, nuestra realidad es el alimento para la formación de las representaciones $\mathrm{y}$, por eso, también es posible describir una sociedad a través de los símbolos creados socialmente. De esa manera es imposible no existir vínculos de nuestra realidad con la comunicación establecida en nuestro medio.

Es posible afirmar que la representación es resultante de nuestras interacciones sociales que, según Moscovici (2007: 21), sirven para "posibilitar que la comunicación sea posible entre los miembros de una comunidad, les dio un código para nombrar y clasificar, sin ambigüedad. Así, se materializa un orden en nuestro universo social y, además, la representación no existiría sin la comunicación.

La estructura de nuestras representaciones no es un modelo idealizado y practicado por un pequeño grupo; existe el consenso de una mayoría. A pesar de las preferencias individuales, los conceptos de afirmaciones generales dependen del consenso. En otras palabras, la representación de la belleza necesita del gusto común para su aprobación, y adquirir sentido para todos. Por lo tanto, los individuos considerados poseedores de "belleza" lo son por cuenta del imaginario colectivo, que evalúa como positivas determinadas imágenes, en detrimento de otras. Pero, la pregunta que surge es si sabemos realmente qué es la belleza, o si somos dirigidos por una élite que define lo que es bueno y lo que es de mal gusto. En esta situación, la creación de estigmas construidos históricamente en contra de la representación de la población negra podría ser analizada como una condición previa para la legitimidad de la creación de creencias sobre razas más evolucionadas.

La jerarquía establecida en el supuesto de falta de representación de imágenes de personas de raza negra también se puede explicar por la estructura social, debido a que los medios de producción están en manos de una pequeña élite, que tiene al blanco como mayoría; este es otro obstáculo para la creación de estrategias que podrían permitir la equidad entre los blancos y los negros. En este sentido, la publicidad, por ejemplo, está diseñada para cumplir con los "efectos de refuerzo", como el concepto de Klapper citado por Brito (2003:2), que se caracteriza por el esfuerzo de la publicidad para generalizar el gusto del público. En esta situación, sería el 
direccionamiento para una estética considerada ideal. Es decir, "imágenes virtuales que representan el medio ambiente no puede existir sin tener que pasar a través de una representación mental de la identidad de su fabricante" (Santaella y Noth, 2001: 13).

Por lo tanto, hay varias preguntas sobre la posibilidad de la presencia de los negros en ciertos anuncios, por ejemplo, viviendas para la clase alta, puesto que no representarían la realidad económica de este grupo. Sin embargo, el problema es que la generalización del gusto estético no puede representar la realidad, ya que el ideal estético no se establece completamente en una clase social.

Es posible afirmar aún que la vulnerabilidad social que sufren las mujeres negras puede ser evaluada debido a su escasa representación. En las imágenes contenidas en los carteles de Itabuna esa representación sigue un orden social desigual que coloca a la mujer negra, a menudo, en la peor posición en distintos ámbitos sociales. Por lo tanto, la escasa representación de ese segmento de la sociedad brasileña en los materiales de nuestro estudio no es sólo una coincidencia o un gusto individual, sino que refleja la posición estructural a la que está sometida la mayoría de estas mujeres, debido al racismo y el machismo construidos históricamente en nuestra sociedad. Así, es legitimo afirmar que la sub representación de la mujer negra en los carteles objeto de este estudio es una especie de "naturalización" de los roles sociales que otorgan a estas mujeres funciones y lugares de subordinación. Este contexto es el resultado de una estructura que intenta imponer una estratificación basada en el color de la piel, con el fin de mantener en los mismos posicionamientos a los grupos que siempre han sido favorecidos por nuestro sistema social.

\section{Conclusiones}

En esta investigación fue posible inferir que los carteles publicitarios en Itabuna representan el "estándar de belleza" socialmente establecido en la sociedad brasileña, lo cual excluye a los individuos que no presenten un fenotipo próximo a los patrones eurocéntricos, los cuales siguen siendo una referencia para la difusión de las imágenes seleccionadas en la publicidad. Por lo tanto, la publicidad legitima una única norma ("ideal") de la belleza; y aunque ese patrón no se materialice totalmente en nuestra realidad, se configura - para muchas personas, y para los medios de comunicación - como "lo ideal". Esto también es posible a causa de las desigualdades socio-económicas que todavía están vinculadas a la cuestión del color de la piel. Ese posicionamiento de los medios de comunicación demuestra que estos pueden ayudar a mantener la creencia, que en este caso sería la superioridad de la élite blanca, ya que el discurso que tiene credibilidad también asegura la creencia en su verdad, a partir de lo que Charaudeau (2006) denomina como "el efecto real". 
En la medida que el fenotipo es una gran referencia para la delimitación de la creación cultural de la superioridad humana en muchos aspectos de nuestra sociedad, la publicidad contenida en los carteles de la ciudad de Itabuna refuerza el gran paradigma que impide la entrada de más imágenes de personas negras. Así, es importante hacer hincapié en el poder que tienen los medios para influir en el imaginario social, porque, incluso, detiene una libertad para hacerlo, la cual le fue otorgada por la propia sociedad. Esto es posible debido a nuestra lógica estructural simbólica, que sirve como base para la creación de sentido en un sistema dado. Aun siendo una lógica de exclusión, fue establecida a partir del consenso social. En consecuencia, el poder simbólico, presente en los medios de comunicación, en la mayoría de los casos puede actuar de manera imperceptible, ya que tiene la función de construir nuestra realidad, para ordenar nuestro mundo social a través de señales difundidas por variadas instituciones, incluso los medios de comunicación.

Las conclusiones de este estudio confirman la hipótesis de que ninguna representación o la representación estereotipada de los negros en los carteles de la ciudad de Itabuna corresponde a una lógica establecida histórica y culturalmente, estructurada bajo los auspicios del racismo, a partir de la cual el rostro y el cuerpo negro no reflejan el "estándar de belleza" socialmente instituido en Brasil (piel blanca, cabellos lisos, labios y narices delgados), y, por lo tanto, explica la invisibilidad y la estigmatización de las personas negras.

\section{Notas}

(1) Recuperado de http://agenciabrasil.ebc.com.br/geral/noticia/2016-12/ibge-negros-sao-17-dos-mais-ricos-e-tresquartos-da-populacao-mais-pobre

(2) Recuperado de http://www.seppir.gov.br/central-de-conteudos/noticias/junho/mapa-do-encarceramento-apontamaioria-da-populacao-carceraria-e-negra-1

(3) Recuperado de http://agenciabrasil.ebc.com.br/educacao/noticia/2016-12/percentual-de-negros-em-universidadesdobra-mas-e-inferior-ao-de-brancos

(4) Recuperado de http://agenciabrasil.ebc.com.br/geral/noticia/2014-10/embargada-para-sexta-feira-denise-griesinger4

(5) Recuperado de http://www.cnj.jus.br/noticias/cnj/80853-populacao-carceraria-feminina-aumentou-567-em-15-anosno-brasil

(6) Recuperado de http://www.revistacapitolina.com.br/a-saude-da-mulher-negra/

(7) En el período Helenístico se observa un creciente naturalismo. Los seres humanos son representados no solamente de acuerdo con la edad y la personalidad, sino también según las emociones y el estado de espíritu de un momento. La gran conquista de la escultura del período Helenístico fue la representación no de una solo figura, sino de grupos de figuras que sugirieran movilidad y fueran bellos de todos los ángulos.

(8) El espectáculo, para Guy Debord, es visto como una relación de personas mediada por imágenes, es decir, representaciones inmediatas que adquieren autonomía y hacen de las personas meros espectadores contemplativos. La sociedad del espectáculo es, también, la invasión de la economía en todas las esferas de la vida. Toda la vida en 
las sociedades en las que reinan las condiciones modernas de producción, se anuncia como una acumulación inmensa de espectáculos. Para el teórico, todo lo que era directamente vivido se desvanecía en el humo de la representación.

\section{Bibliografía}

Abrahão, B. O. de Lacerda y Soares, Antonio J. Gonçalves (2011). O corpo negro e ospreconceitos impregnados na cultura: uma análise dos estereótipos raciais presentes na sociedade brasileira a partir do futebol. Movimento, 17(4) pp. 265-280. Recuperado de

http://www.ludopedio.com.br/v2/content/uploads/051608_Vol.\%2017,\%20No\%204\%20( 2010)_2.pdf

Brito, P. M. (2003). A evolução midiática do belo: transformações e tendências da estética do corpo feminino na sociedade contemporânea. (Tesis de maestria). Maestría en Comunicación Universidade Metodista de São Paulo. São Paulo. Recuperado de https://www.metodista.br/revistas/revistas-ims/index.php/CSO/.../3531

Charaudeau, P. (2006). Discurso das mídias. São Paulo: Contexto.

Costa, S. (2002). A construção sociológica da cor. Revista estudo afro-asiáticos, 24(1), pp. 3521.

Cunha, E. M. García de Pinto da (2014). Afodescendientes brasileños: panorama actual de sus condiciones de vida y de salud y sus desafíos. En Wong, L.; Rodriguez L. y J. A. Sánchez (Comp.). Situación de la población afro-descendiente e indígena en América Latina-puntos de reflexión para el debate sobre Cairo + 20. Belo Horizonte: ALAP.

D’Adesky, J. (2001). Pluralismo Étnico e Multiculturalismo: Racismo e Anti- racismo no Brasil. Rio de Janeiro: Pallas.

Debord, G. (1998). La sociedad del espectáculo. Santiago de Chile: Ediciones Naufragio.

IPEA (2013). Dossiê mulheres negras: retrato das condições de vida das mulheres negras no Brasil, Brasília, Ipea. Recuperado de: http://ipea.gov.br/portal/index.php?option=com_content\&id=20978

Eco, U. (2004). História da beleza. Recuperado de: http://pt.scribd.com/doc/139565230/HISTORIA-DA-BELEZA-pdf-pdf

Fanon, F. (2008). Pele negra, máscaras brancas. Salvador: Edufba.

Góes, W. L. (2015). Racismo, eugenia no pensamento conservador brasileiro: a proposta de povo em Renato Kehl. (Tesis de maestría). Maestría en Filosofía, Universidade Estadual Paulista.

Gomes, N. D. (2001). Publicidade ou propaganda? É isso aí! Revista FAMECOS: mídia, cultura $e$ 
cidadania, 1(16), Porto Alegre.

Goldenberg, M. (1997). A arte de pesquisar: como fazer pesquisa qualitativa em ciências sociais. Rio de Janeiro: Record.

Guimarães, A. S. A (2004). Preconceito e Discriminação. São Paulo: 34 Itd.

Lakatos, E. M.; Marconi, M. de A (2001). Metodologia científica. São Paulo: Atlas.

Mattos, I. G. de (2009). Estética negra afirmativa:corpo negro e educação física. Salvador: Eduneb.

Moscovici, S. (2007). Representações sociais: investigação em psicologia social. Rio de Janeiro: Vozes.

Nascimento, Elisa L. (2003). O sortilégio da coridentidade, raça e gênero no Brasil. São Paulo: Summus.

Pinho, J. B. (1990). Propaganda institucional: usos e funções da propaganda em relações públicas. São Paulo: Summus.

Retondar, A. M. (2007). A mundialização do consumo: publicidade e cultura na era da globalismo, XXVI Congresso da Associação Latono-americana de Sociologia, Guadalajara. Recuperado de http://www.aacademica.com/000-066/306.pdf

Santt' Ana, J. V. B. De (2014/2015). A representação da pessoa negra em imagens de comércios do nordeste goiano. Revista Urutágua, 31, pp.41-54.

Santaella, L. y Noth, W. (2001). Imagens: cognição, semiótica e mídia. São Paulo: Iluminares.

Stronzenberg, I. (julio de 2005). O apelo da cor: percepções dos consumidores sobre as imagens da diferença racial na propaganda brasileira. Revista Comunicação, mídia e consumo, 2(4), pp. 199-220. 